\title{
An experimental study of VEGF induced changes in vasoactivity in pig retinal arterioles and the influence of an anti-VEGF agent
}

\author{
Er-Ning Su ${ }^{1,2}$, Stephen J Cringle ${ }^{1,2}$, lan L McAllister ${ }^{1}$ and Dao-Yi Yu ${ }^{1,2^{*}}$
}

\begin{abstract}
Background: Vascular endothelial growth factor (VEGF) plays an important role in ocular physiology. Anti-VEGF agents are now used for treatment of common retinal diseases. This study characterises the vasoactive properties of VEGF in isolated perfused pig retinal arterioles under normal tone or endothelin-1 (ET-1) pre-contracted conditions and determines the influence of an anti VEGF agent on VEGF induced vasoactivity.

Methods: An isolated perfused retinal arteriole preparation was used. The outer diameter of retinal vessels was monitored at 2 second intervals in response to VEGF and the anti VEGF agent, bevacizumab. The effect of intraluminal delivery of VEGF was determined over a wide concentration range $\left(10^{-16}\right.$ to $\left.10^{-7} \mathrm{M}\right)$ both with and without pre-contraction with ET-1 $\left(3 \times 10^{-9} \mathrm{M}\right)$. Bevacizumab $\left(0.35 \mathrm{mg} \mathrm{mL}^{-1}\right)$ was applied extraluminally to determine the influence of bevacizumab on VEGF induced vasoactive changes on ET-1 pre-contracted vessels.
\end{abstract}

Results: In retinal arterioles with normal tone, VEGF induced a concentration dependent contraction at low concentrations, reaching $93.5 \%$ at $10^{-11} \mathrm{M}$ and then contraction was reduced at higher concentrations, recovering to $98.1 \%$ at $10^{-7} \mathrm{M}$. VEGF produced a potent concentration dependent vasodilatation in arterioles pre-contracted with ET-1. VEGF induced vasodilatation in arterioles pre-contracted with ET-1 was significantly inhibited by bevacizumab.

Conclusions: VEGF induced vasoactive changes in pig retinal arterioles are dependent on concentration and vascular tone. Bevacizumab inhibits VEGF-induced vasodilatation in pre-contracted arterioles.

\section{Background}

Vascular endothelial growth factor (VEGF) is a protein with a high specificity for endothelial cells. In addition to its role in angiogenesis, VEGF also serves multiple important functions including pro-angiogenesis [1], enhancement of vascular permeability [2], changing vascular tone [3-7], and promotion of cell survival [8], division [9], and differentiation [10].

Neovascular ocular diseases represent a major cause of vision loss in diseases such as proliferative diabetic retinopathy, age-related macular degeneration, retinopathy of prematurity and retinal vascular occlusions [11]. Elevated VEGF has been found in these diseases [12,13].

\footnotetext{
* Correspondence: dyyu@cyllene.uwa.edu.au

${ }^{1}$ Centre for Ophthalmology and Visual Science, The University of Western Australia, Perth, Australia

${ }^{2}$ ARC Centre of Excellence in Vision Science, The University of Western Australia, Perth, Australia
}

\section{Biomed Central}

(c) 2012 Su et al.; licensee BioMed Central Ltd. This is an Open Access article distributed under the terms of the Creative Commons Attribution License (http://creativecommons.org/licenses/by/2.0), which permits unrestricted use, distribution, and reproduction in any medium, provided the original work is properly cited.
VEGF has been considered to be an important pathogenic factor as well as a therapeutic target in ocular neovascularisations and associated changes [14]. Given the introduction of therapeutic interventions using VEGF antibodies, VEGF antagonists and VEGF receptor antagonists in clinical ophthalmology, it is more important than ever to understand the normal functions served by VEGF and to understand the consequences of shortand long-term intervention with VEGF inhibitors.

It is critical to address the vasoactive properties of VEGF and anti VEGF agents in retinal vessels, particularly in cases of ischemic ocular diseases. However, little quantitative information is available about the vasoactive properties of VEGF at the retinal arteriole level.

The question addressed in this study is whether VEGF induces direct effects on retinal arterioles and whether it can be influenced by anti-VEGF agents. Our hypotheses are that VEGF can induce concentration dependent 
effects on retinal arterioles and that these effects can be modulated by anti VEGF agents. In the present study we investigate the vasoactive properties of VEGF in an isolated perfused porcine retinal arteriole preparation. Porcine retinal arteries have been shown to exhibit similar vasoactive properties to human retinal arteries with a range of vasoactive agents $[15,16]$.

\section{Methods}

\section{Isolated perfused retinal arteriole}

Pig eyes were obtained from a local abattoir and picked up by our technician. Following enucleation, the eyes were placed in a sealed bottle of oxygenated Krebs solution and kept on ice during transfer to the laboratory ( 60 minutes). All procedures conformed to the EU Directive 2010/63/EU for animal experiments. The dissection, cannulation, perfusion, monitoring and vessel diameter measuring system are fully described in our previous publications using isolated perfused retinal arterioles [15,17-19] and will be only briefly described here.

\section{Dissection and cannulation of vessels}

The eyes were sectioned at pars plana ciliaris, separating the anterior segment and adherent vitreous body from the posterior pole with the aid of a dissecting microscope. The retina, choroid and sclera were divided into quadrants. The retina was then separated from the underlying choroid and sclera. A quadrant of retina was then placed on a hollowed glass slide containing Krebs solution. An individual first-order retinal arteriole was dissected free of retinal tissue with a micropipette. Typically, two arterioles were harvested from each eye. A segment of retinal arteriole $(\sim 100 \mu$ m outer diameter $)$ about $800-1500 \mu \mathrm{m}$ long and containing only one relatively large side branch was selected. This arterial segment was then relocated to an incubation chamber (PDMI-2, Medical System Corp, New York, USA) mounted on the stage of an inverted microscope (Nikon Diaphot-TMD, Japan). The chamber contained $5 \mathrm{~mL}$ Krebs solution. Temperature was maintained at $37^{\circ} \mathrm{C}$ and the incubating solution equilibrated with $95 \% \mathrm{O}_{2}$, $5 \% \mathrm{CO}_{2}$ so as to maintain $\mathrm{PO}_{2}, \mathrm{PCO}_{2}$ and $\mathrm{pH}$ of the incubating solution.

The arterial segment was then cannulated at both ends using the customized pipette and manipulating system shown schematically in Figure 1 . The vessel was then perfused through the proximal end in the orthograde direction at a constant flow of $5 \mu \mathrm{min}^{-1}$. The distal end was perfused at $0.3 \mu \mathrm{lmin}^{-1}$ in the retrograde direction to avoid drug entrapment. Both flows exited through the side branch. The vessel was visualized on a video monitor and a pre-programmed computer algorithm was used to measure the external vessel diameter at user selected locations from a frame grabbed image at two second intervals. The vessel was left to stabilize for 30 minutes prior to any drug study. A fresh arteriole was used for each experiment.

\section{Intraluminal and extraluminal drug delivery}

Intraluminal drug delivery was administered as a $5 \mu \mathrm{l}$ bolus into the perfusate stream via an HPLC type sample injector valve. This system allowed the bolus to enter the perfusate stream without pressure artefacts. A switch on the HPLC valve signalled the time of injection of the bolus to the computer and chart recorder. The size, and hence the duration of the bolus, was sufficient for vasoactive responses of the vessel to stabilise. Extraluminal drug delivery was accomplished by direct pipetting into the incubating solution to achieve the required concentration without washing out the bath. The concentration range used of VEGF was $10^{-16}-10^{-7} \mathrm{M}$ for intraluminal delivery. This range covers the concentration range used for VEGF vasoactivity studies in other organs $[3,5,6,20,21]$. The high cost of VEGF prohibited high concentration levels of VEGF in the relatively large volume of the incubation bath, so only intraluminal VEGF was tested. In a set of preliminary experiments there was no statistically significant difference in VEGF induced vasoactivity in porcine retinal arterioles between intraluminal and extraluminal application (unpublished data). To mimic vitreous injection, bevacizumab was applied extraluminally. All data is presented as normalised vessel diameter percentage, where the data is normalised to the diameter of the vessel prior to any drug administration.

\section{Solutions and agents}

Vessels were usually bathed and perfused with normal Krebs solution of composition (in $\mathrm{mM}$ ) $\mathrm{NaCl} \mathrm{119;} \mathrm{KCl}$ 4.6; $\mathrm{CaCl}_{2}$ 1.5; $\mathrm{MgCl}_{2}$ 1.2; $\mathrm{NaHCO}_{3}$ 15; $\mathrm{NaH}_{2} \mathrm{PO}_{4}$ 1.2; Glucose 6 . All chemicals and vasoactive agents used were obtained from Sigma Chemicals (St Louis, MO) except recombinant human VEGF which was purchased from Invitrogen, CA and Bevacizumab (Avastin; F. HoffmannLa Roche, Ltd., Basel, Switzerland) prepared by the Pharmacy Department, Sir Charles Gairdner Hospital, Perth, Australia. The VEGF was dissolved in $\mathrm{Na}^{+}-\mathrm{Krebs}$ solution. Stock solutions were stored at $-70^{\circ} \mathrm{C}$ and fresh dilutions were made daily.

\section{Experiment protocol}

After equilibration, an intraluminal injection of $124 \mathrm{mM}$ $\mathrm{K}^{+}$Krebs was given to confirm retinal vessel viability. Vessels were rejected if the contraction response did not result in a diameter of less than $85 \%$ of the uncontracted baseline diameter.

The effect of a wide range of intraluminal VEGF concentrations $\left(10^{-16}\right.$ to $\left.10^{-7} \mathrm{M}\right)$ was determined in 


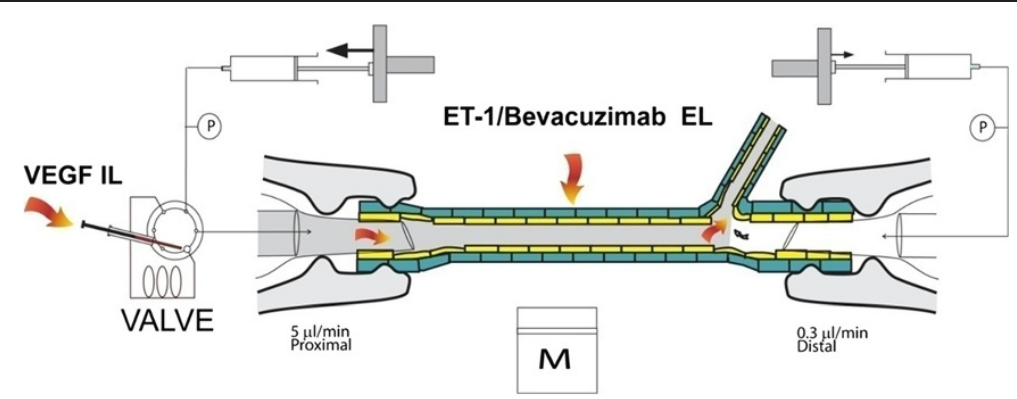

Figure 1 Schematic representation of the isolated perfused vessel system. The isolated pig retinal arteriole is cannulated at both ends and perfused intraluminally whilst maintained in a temperature controlled bath on the stage of an inverted microscope. VEGF can be administered intraluminally via an HPLC valve. ET-1 and bevacizumab are delivered extraluminally by addition to the bathing solution. Vessel diameter is monitored every two seconds by an automated frame grabbing and vessel diameter measurement routine.

uncontracted retinal arterioles and in arterioles contracted with extraluminal ET-1. When extraluminal application of ET-1 $\left(3 \times 10^{-9} \mathrm{M}\right)$ was used to pre-contract the vessels, the ET-1 remained in the bath during all subsequent drug administrations. Pre-contracted vessels can be sustained over the experimental period $[19,22,23]$.

Bevacizumab (0.35 $\left.\mathrm{mg} \mathrm{mL}^{-1}\right)$ was applied extraluminally after administering extraluminal ET-1 which remained in the bath. This concentration of bevacizumab is comparable to that used clinically $[24,25]$.

\section{Statistics}

All statistical testing was performed using the statistics program SigmaStat (Jandel Scientific Software, San Raphael, CA, USA). The significance of any drug induced concentration dependent changes was tested using one way ANOVA, with significance acceptance level of $\mathrm{p}<0.05$ for the $\mathrm{F}$ value. When comparing concentration response curves, the two way ANOVA using drug concentration as the second factor was used with an acceptance level of $\mathrm{P}<0.05$. When appropriate, Student's t test was employed. All mean data is expressed as mean \pm standard error, and all error bars on graphs are also standard errors. The $n$ number refers to the number of arterioles.

\section{Results}

The mean baseline diameter of the porcine retinal arterioles prior to any drug administration was $106.4 \pm 1.4$ $\mu \mathrm{m}(\mathrm{n}=69)$. VEGF induced changes in the vessel diameter were not mono-phasic. A wide range of VEFG concentrations $\left(10^{-16}\right.$ to $\left.10^{-7} \mathrm{M}\right)$ was administrated to cover this complex change. Average normalised vessel diameter following intraluminal delivery of a range of VEGF concentrations is shown in Figure 2. VEGF produced a significant concentration dependent changes in vessel diameter $(\mathrm{p}<0.001)$. Vessel contraction was maximal at $10^{-11} \mathrm{M}$ VEGF, reaching $93.5 \pm 1.5 \% \quad(\mathrm{n}=24)$. With higher concentrations, VEGF produced contraction was reduced, reaching only $98.1+1.6 \%$ at $10^{-7} \mathrm{M}$.

However, VEGF induced vasoactivity was altered in prevailing experimental condition. In pre-contracted retinal arterioles, VEGF induced mono-phasic vessel dilatation. ET-1 $\left(3 \times 10^{-9} \mathrm{M}\right)$ was administrated extraluminally, producing an average vessel contraction to $69.9 \pm 1.7 \%$. Figure 3 shows the mean normalised diameter change with intraluminal delivery of increasing concentrations of VEGF in ET-1 pre-contracted retinal arterioles. VEGF produced a significant concentration dependent dilatation $(\mathrm{p}<0.001)$. There was a significant dilatation at $10^{-12} \mathrm{M}$ and above when compared with ET-1 precontraction alone. The average vessel diameter reached $96.5 \pm 2.7 \%(\mathrm{n}=16)$ at $10^{-7} \mathrm{M}$.

To determine whether bevacizumab can inhibit VEGF induced vasodilatation, a clinical concentration of bevacizumab used for vitreous injection was added extraluminally before VEGF application in ET-1 pre-contracted vessels. Figure 4 shows the mean normalised diameter change with intraluminal delivery of increasing concentrations of VEGF and extraluminal application of both ET-1 $\left(3 \times 10^{-9} \mathrm{M}\right)$ and bevacizumab $\left(0.35 \mathrm{mg} \mathrm{mL}^{-1}\right)$. ET1 administration produced an average vessel contraction to $64.8 \pm 1.9 \%(n=19)$ which was not statistically different than that found previously. Adding bevacizumab into the bath did not produce a significant change in vessel diameter $(65.4 \pm 1.9 \%, \mathrm{p}=0.815)$. With the presence of bevacizumab in the bath, VEGF still produced a concentration dependent dilatation $(\mathrm{p}<0.001)$ in ET-1 pre contracted vessels. The averaged vessel diameter was significantly increased at $10^{-12} \mathrm{M}$ and above when compared with that before administration of VEGF. However, the average increase in diameter with VEGF administration was significantly less than that without the addition of bevacizumab $(\mathrm{p}=0.002)$, reaching only $77.7 \pm 1.4 \%$ at $10^{-7} \mathrm{M}$. Bevacizumab therefore inhibits VEGF induced vasodilatation responses in precontracted vessels. 


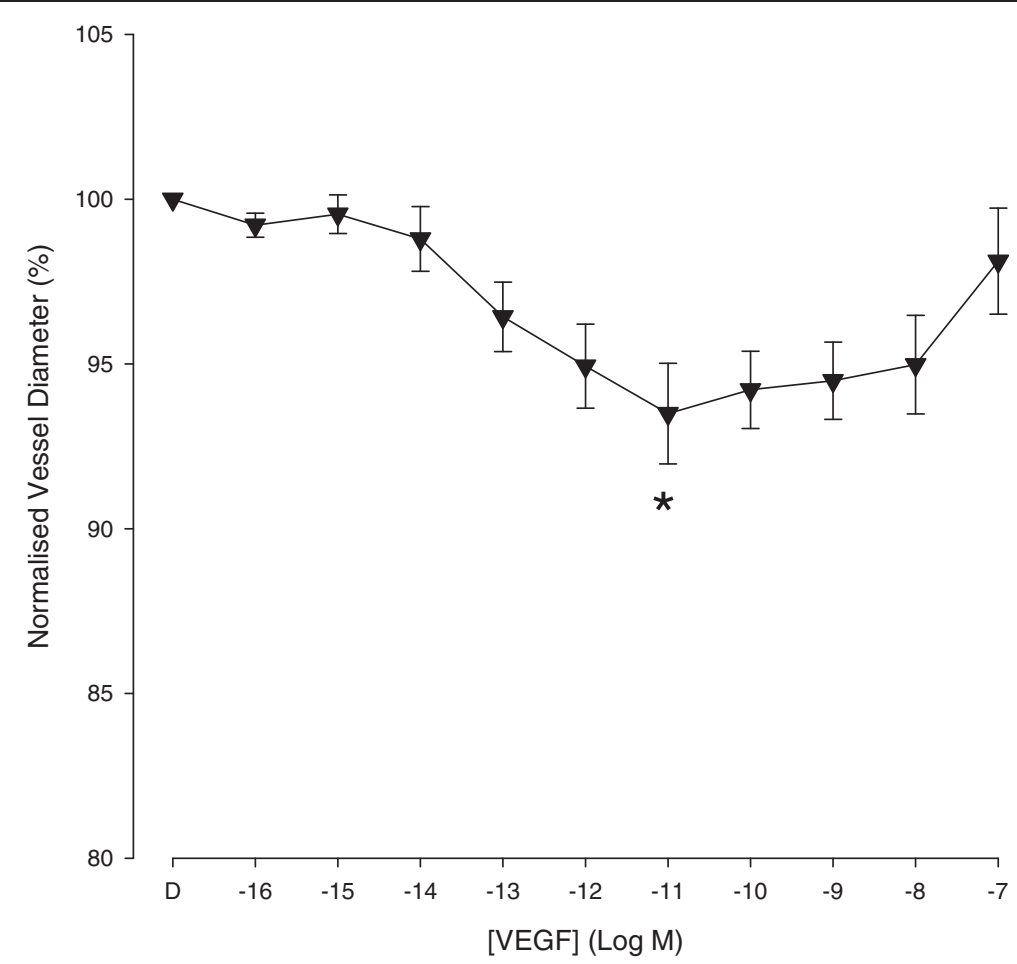

Figure 2 Concentration response curve of VEGF in retinal arterioles with normal tone. With intraluminal delivery over a concentration range $\left(10^{-16}-10^{-7} \mathrm{M}\right)$ the level of contraction reduced at higher VEGF concentration, producing a significant dilatation when compared to the maximally contracted state at $10^{-11} \mathrm{M}$ VEGF. ${ }^{*}$ Denotes a significant contraction compared to initial baseline $(p<0.05)$.

\section{Discussion}

This study provides detailed information regarding VEGF induced direct vasoactive changes in both normal tone and pre-contracted retinal arterioles and demonstrates that VEGF exhibits vasoactive effects on porcine retinal arterioles. It has been strongly evidenced that the vasoactive properties induced by VEGF in retinal arterioles are clearly depend on the concentration and vessel conditions before the application of VEGF. The results also show that bevacizumab can inhibit the VEGF induced vasodilatations in pre contracted retinal arterioles. These results may be important not only to illuminate and interpret some consequences from patients treated by anti VEGF agents, but also to provide some possible clues as to how to avoid some side effects.

Anti-VEGF agents have been extensively used in ocular diseases in order to inhibit retinal neovascularisation [13,14,26-28].

In considering therapeutic benefits and side effects of VEGF, it is important to bear in mind that VEGF has multiple physiological and pathological roles, and multiple factors could be influenced after modulation of VEGF activity at the systemic or individual organ level. In ocular neovascularisation and ischemic diseases, we need to consider changes in angiogenesis and permeability, and also blood flow. It has been reported that intravitreal ranibizumab could induce retinal circulation disturbances in patients with neovascular age-related macular degeneration [27], neovascular glaucoma [29], retinal vein occlusion [30], and diabetic retinopathy [31]. It is important to determine VEGF induced vasoactivity on retinal arterioles before addressing the possible effects of vitreal bevacizumab injection on the retinal circulation. Our results obtained from retinal arteriole are remarkably different than that from previous reports in other organs. Our results show that the vasoactive properties induced by VEGF in vessels without precontraction appear to be mildly contractile at low concentrations ( $\sim 5 \%$ reduction in the vessel diameter) and less contractile at higher concentrations of VEGF (almost reaching the original diameter). However, the results obtained from other organs show dilatation responses of arteries, for example coronary arteries $[3,4]$, placental lobule [32], uterine arteries [20], and pulmonary arteries [21]. One possible explanation is a difference in vasoactive properties between the retinal arteriole and peripheral vessels that were used in most of the previous studies. Retinal blood vessels are not innervated [33-37]. Retinal arteriole tone is mainly regulated by local factors. The mediators derived from the endothelial cells and retinal tissue can be considered as local regulators in addition to physical and 


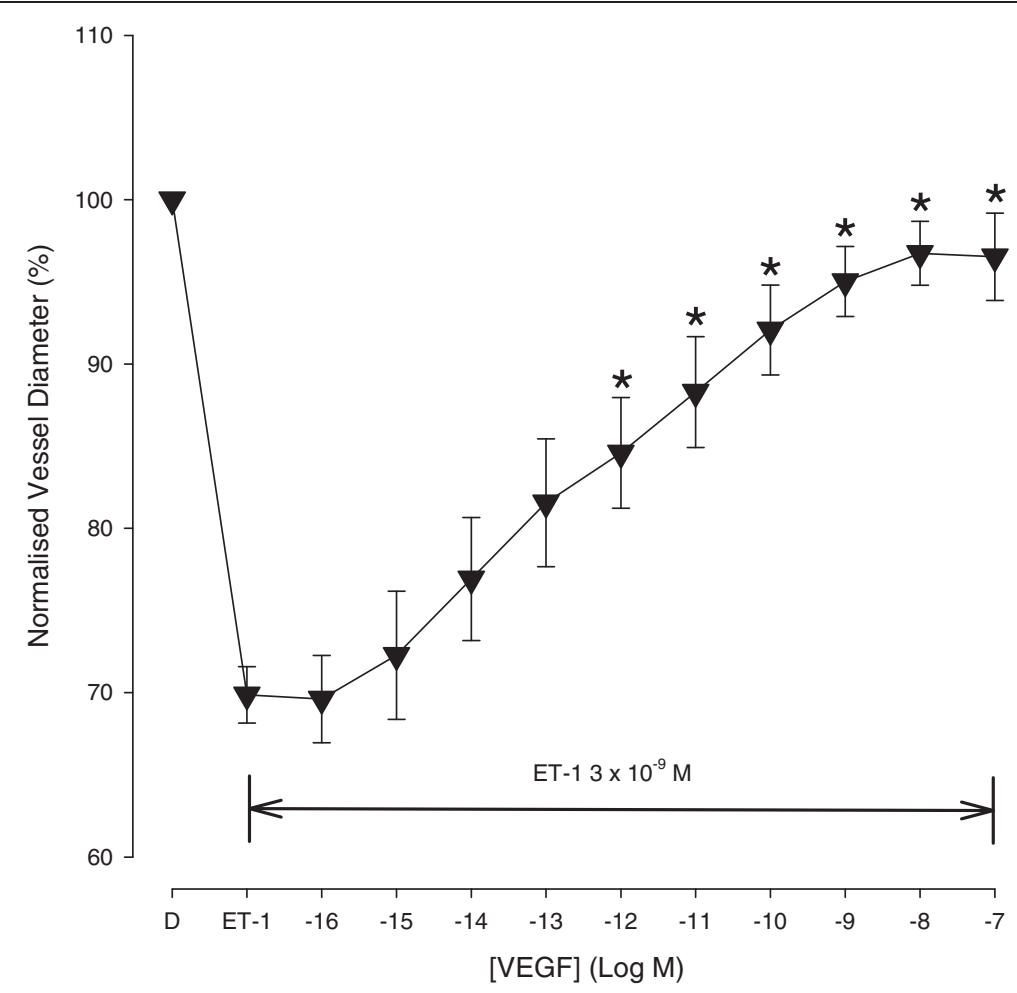

Figure 3 Concentration response curve of VEGF from ET-1 pre-contracted retinal arterioles. In isolated pig retinal arterioles pre-contracted with ET-1 $\left(3 \times 10^{-9} \mathrm{M}\right)$ VEGF exhibited a concentration dependent vasodilatation response. * Denotes a significant dilatation compared to contracted baseline $(p<0.05)$.

metabolic influences [38,39]. However, the effective concentration levels in most previous studies are similar to that in our study indicating that vasoactive effect starts at concentrations as low as $\sim 10^{-12} \mathrm{M}[3,6,20,21]$.

To our knowledge, the effect of VEGF in precontracted vessels has not previously been studied. Our results demonstrate that in ET-1 pre-contracted vessels, VEGF induced a potent concentration dependent vasodilatation response which was inhibited by bevacizumab at a similar concentration to that used clinically. The rationale of studying the effect of VEGF on pre-contracted vessels is that the majority of patients treated by bevacizumab are aged, and may have cardiovascular disease and increased vessel tone. Furthermore, VEGF levels in most ocular neovascular diseases are increased. Bevacizumab is a full-length, humanized monoclonal antibody directed against all the biologically active isoforms of vascular endothelial growth factor (VEGF-A). It could be expected that bevacizumab may modulate the retinal vessel tone. Our results demonstrated that bevacizumab can inhibit VEGF induced vasodilatation if the vessel is pre-contracted. Retinal ischemia in some patients may therefore be exacerbated by VEGF inhibition.

Since 2005 the experience with bevacizumab and other anti VEGF agents in ophthalmology has accumulated rapidly. Therapeutic benefits in neovascular ocular diseases have been demonstrated. However, despite the excitement, a number of critical issues have been raised. Two major issues need to be urgently addressed. Firstly, regrowth of new vessels is often found and permanent regression of neovascularization is rare, requiring multiple injections of anti VEGF agent. Secondly, associated ischemia after application of anti VEGF agents has been found in various neovascular ocular diseases. These issues may be interlinked. Neovascularisation in the eye and other organs occurs by both vasculogenesis and angiogenesis. It is now known that vasculogenesis occurs in the adult as endothelial precursor cells derived from the bone marrow enter the circulation in response to ischemic injury. In addition, hypoxia regulated factors are the key mediators of endothelial precursor cells and resident endothelial cells [11]. Ideal treatments of neovascular ocular diseases should not only target reduced neovascularisation and vascular permeability, but also relieve the retinal ischemia/hypoxia if possible. The retina is a functionally active tissue, with arguably the highest oxygen demand tissue per weight, yet the retina has a very limited blood supply from the retinal circulation [40-44]. Recently, reduced retinal perfusion has been demonstrated following anti VEGF treatment in eyes with branch retinal vein occlusion [45]. Anti VEGF treatment further reduces retinal perfusion causing more 


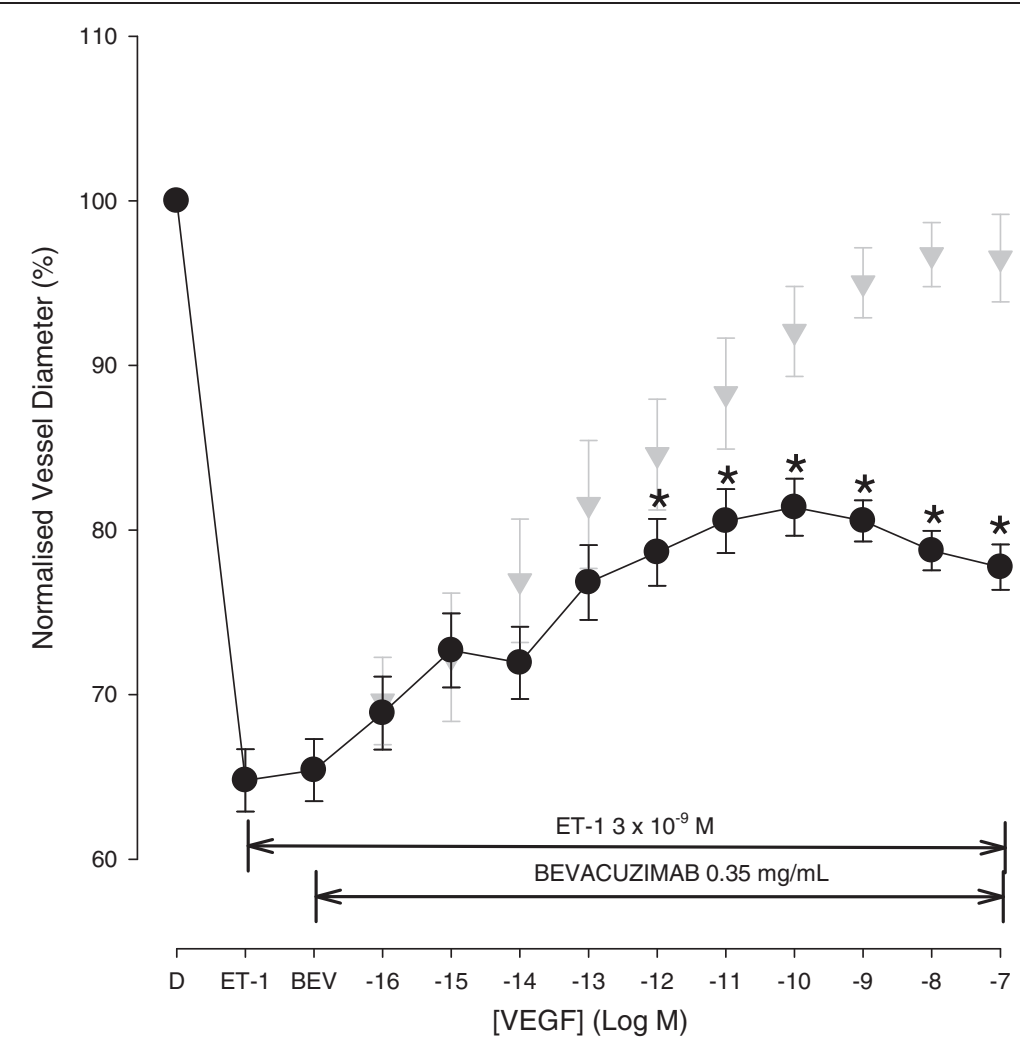

Figure 4 Concentration response curve of VEGF from ET-1 pre-contracted retinal arterioles with extraluminal bevacizumab. In isolated pig retinal arterioles pre-contracted with ET-1 $\left(3 \times 10^{-9} \mathrm{M}\right)$ VEGF induced a concentration dependent vasodilation response was significantly inhibited by bevacizumab. For ease of comparison the data showing the VEGF induced dilatation in the absence of bevacizumab is also included (grey symbols). * Denotes a significant dilatation compared to contracted baseline $(p<0.05)$.

severe ischemia/hypoxia which could be the cause of the regrowth of new vessels. The potential long-term effects of anti VEGF induced vasoconstriction may need to be considered.

An important question needing to be addressed is how to avoid the associated ischemic retinal and choriocapillaris changes after intraocular administration of anti VEGF agents [27,29-31]. Our results show that bevacizumab is able to inhibit VEGF induced potent vasodilatation. It is possible that the anti-VEGF agent, bevacizumab may inhibit the vasodilatation by VEGF after vitreous injection. As a consequence, retinal blood flow could be reduced. Our results also show that VEGF induced vasodilatation only occurs in ET-1 pre contracted vessels. It could be assumed that in the cases in these clinical reports, VEGF may act as a vasodilator that counterbalances contractile vessel effects caused by the original disease before anti-VEGF injection. However, anti-VEGF agent could inhibit VEGF induced vasodilatation, and as consequence, vasoconstriction could be present. It is well known that VEGF has several family groups but it is the VEGF-A family that is principally involved in the regulation of vasoactive tone. VEGF-A has at least seven splice variants [46]. It could be favourable if an anti-VEGF agent could be chosen that is not involved in the regulation of vasoactive tone, or better still, one that can potentially improve retinal blood flow. The design of a new anti VEGF agent should also consider the differences of vasoactive properties between the retinal vasculature and that in other organs, as well as between normal tone and pre-contracted vessels. In addition, the concentration of anti-VEGF agent also needs to be considered, and case selection may be important. Some cases in which ischemia is predicted, such as ischemic central retinal vein occlusion, added caution in the use of anti-VEGF treatment may be warranted in order to avoid exacerbating retinal ischemia.

There are undoubtedly complex mechanisms regulating ocular and serum levels of VEGF in health and disease. The increasing use of anti-VEGF drugs to treat retinal and choroidal neovascularisation, should be accompanied by further studies of VEGF induced changes in vascular tone in order maximise the therapeutic benefits and to minimise unwanted side effects.

\section{Conclusions}

Using an isolated porcine retinal arteriole preparation we have demonstrated that VEGF causes variable dose 
dependent effects on arterioles with normal tone, but a potent vasodilatation in arterioles pre-contracted with endothelin-1. The VEGF dilatation effects are significantly counteracted by the anti-VEGF agent bevacizumab. Given the widespread expression of VEGF in tissues and the importance of VEGF for neural cells as well as the endothelium, future detailed studies on biological parameters will be required to elucidate more completely the role of VEGF in the eye.

\section{Competing interests}

The authors declare that they have no competing interests.

\section{Acknowledgements}

We wish to thank Dean Darcey for his expert technical assistance. Grant support was provided by the National Health and Medical Research Council of Australia (Dao-Yi Yu, lan McAllister, and Stephen Cringle), and by the Australian Research Council Centre of Excellence in Vision Science (Dao-Yi Yu and Stephen Cringle).

\section{Authors' contributions}

ES performed the experimental work, the initial data analysis, and the initial preparation of the manuscript. DY and SJC designed the study, participated in the experimental work, completed the data analysis, and refined the manuscript. IM assisted with the experiment design and manuscript refinement. All authors read and approved the final manuscript.

Received: 08 December 2011 Accepted: 29 May 2012

Published: 29 May 2012

\section{References}

1. Connolly DT, Heuvelman DM, Nelson R, Olander JV, Eppley BL, Delfino JJ, et al: Tumor vascular permeability factor stimulates endothelial cell growth and angiogenesis. J Clin Invest 1989, 84:1470-1478.

2. Senger DR, Galli SJ, Dvorak AM, Perruzzi CA, Harvey VS, Dvorak HF: Tumor cells secrete a vascular permeability factor that promotes accumulation of ascites fluid. Science 1983, 219:983-985.

3. Ku DD, Zaleski JK, Liu S, Brock TA: Vascular endothelial growth factor induces EDRF-dependent relaxation in coronary arteries. Am J Physiol 1993, 265:H586-H592.

4. Hariawala MD, Horowitz JR, Esakof D, Sheriff DD, Walter DH, Keyt B, et al: VEGF improves myocardial blood flow but produces EDRF-mediated hypotension in porcine hearts. J Surg Res 1996, 63:77-82.

5. Ni Y, May V, Braas K, Osol G: Pregnancy augments uteroplacental vascular endothelial growth factor gene expression and vasodilator effects. Am J Physiol 1997, 273:H938-H944.

6. Liu MH, Jin HK, Floten HS, Yang Q, Yim AP, Furnary A, et al: Vascular endothelial growth factor-mediated endothelium-dependent relaxation is blunted in spontaneously hypertensive rats. J Pharmacol Exp Ther 2001, 296:473-477.

7. Maynard SE, Min JY, Merchan J, Lim KH, Li J, Mondal S, et al: Excess placental soluble fms-like tyrosine kinase 1 (sFlt1) may contribute to endothelial dysfunction, hypertension, and proteinuria in preeclampsia. J Clin Invest 2003, 111:649-658.

8. Kliche $\mathrm{S}$, Waltenberger J: VEGF receptor signaling and endothelial function. IUBMB Life 2001, 52:61-66.

9. Ferrara N, Henzel WJ: Pituitary follicular cells secrete a novel heparinbinding growth factor specific for vascular endothelial cells. Biochem Biophys Res Commun 1989, 161:851-858.

10. Charnock-Jones DS, Sharkey AM, Boocock CA, Ahmed A, Plevin R, Ferrara N, et al: Vascular endothelial growth factor receptor localization and activation in human trophoblast and choriocarcinoma cells. Biol Reprod 1994, 51:524-530

11. Afzal A, Shaw LC, Ljubimov AV, Boulton ME, Segal MS, Grant MB: Retinal and choroidal microangiopathies: therapeutic opportunities. MicrovasC Res 2007, 74:131-144.
12. Noma H, Funatsu H, Mimura T, Harino S, Hori S: Vitreous levels of interleukin- 6 and vascular endothelial growth factor in macular edema with central retinal vein occlusion. Ophthalmology 2009, 116:87-93.

13. Noma H, Minamoto A, Funatsu H, Tsukamoto H, Nakano K, Yamashita H, et al: Intravitreal levels of vascular endothelial growth factor and interleukin- 6 are correlated with macular edema in branch retinal vein occlusion. Graefes Arch Clin Exp Ophthalmol 2006, 244:309-315.

14. Chakrabarti S, Cukiernik M, Hileeto D, Evans T, Chen S: Role of vasoactive factors in the pathogenesis of early changes in diabetic retinopathy. Diabetes Metab Res Rev 2000, 16:393-407.

15. Yu D-Y, Su EN, Cringle SJ, Alder VA, Yu PK, DeSantis L: Effect of beta blockers and $\mathrm{Ca} 2+$ entry blockers on ocular vessels. In Glaucoma ocular blood flow and drug treatment. Edited by Drance S. Amsterdam: Kugler Publications; 1997:123-134

16. Su EN, Yu D-Y, Cringle SJ, Alder VA, Yu PK, Buckland L: Preservation of vasoactive properties of human retinal arteries after cryopreservation. Aust N Z J Ophthalmol 1998, 26:S59-S61.

17. Su EN, Yu D-Y, Cringle SJ: Histamine induces opposing vasoactive effects at different levels of the ocular vasculature. Curr Eye Res 2005, 30:205-212.

18. Yu D-Y, Alder VA, Cringle SJ, Su EN, Yu PK: Vasoactivity of intraluminal and extraluminal agonists in perfused retinal arteries. Invest Ophthalmol Vis Sci 1994, 35:4087-4099.

19. Yu D-Y, Su E-N, Cringle SJ, Yu PK: Isolated preparations of ocular vasculature and their applications in ophthalmic research. Prog Retina Eye Res 2003, 22:135-169.

20. Itoh S, Brawley L, Wheeler T, Anthony FW, Poston L, Hanson MA: Vasodilation to vascular endothelial growth factor in the uterine artery of the pregnant rat is blunted by low dietary protein intake. Pediatr Res 2002, 51:485-491.

21. Jacobs ER, Zhu D, Gruenloh S, Lopez B, Medhora M: VEGF-induced relaxation of pulmonary arteries is mediated by endothelial cytochrome P-450 hydroxylase. Am J Physiol Lung Cell Mol Physiol 2006, 291:L369-L377.

22. Yu D-Y, Su EN, Cringle SJ, Schoch C, Percicot CP, Lambrou GN: Comparison of the vasoactive effects of the docosaoid unoprostone and selected prostanoids on isolated perfused retinal arterioles. Invest Ophthalmol Vis Sci 2001, 42:1499-1504.

23. Yu DY, Su EN, Cringle SJ, Alder VA, Yu PK, DeSantis L: Effect of betaxolol, timolol and nimodipine on human and pig retinal arterioles. Exp Eye Res 1998, 67:73-81.

24. Sato T, Emi K, Ikeda T, Bando H, Sato S, Morita S, et al: Severe intraocular inflammation after intravitreal injection of bevacizumab. Ophthalmology 2010, 117:512-516.

25. Gurwood AS: Is intravitreal bevacizumab use safe for AMD? Optometry. J Am Optom Assoc 2007, 78(1):4.

26. Weis SM, Cheresh DA: Pathophysiological consequences of VEGF-induced vascular permeability. Nature 2005, 437:497-504.

27. Papadopoulou DN, Mendrinos E, Mangioris G, Donati G, Pournaras CJ: Intravitreal ranibizumab may induce retinal arteriolar vasoconstriction in patients with neovascular age-related macular degeneration. Ophthalmology 2009, 116:1755-1761.

28. Kabbinavar F, Hurwitz HI, Fehrenbacher L, Meropol NJ, Novotny WF, Lieberman G, et al: Phase II, randomized trial comparing bevacizumab plus fluorouracil (FU)/leucovorin (LV) with FU/LV alone in patients with metastatic colorectal cancer. J Clin Oncol 2003, 21:60-65.

29. Yokoyama K, Choshi T, Kimoto K, Shinoda K, Nakatsuka K: Retinal circulatory disturbances following intracameral injection of bevacizumab for neovascular glaucoma. Acta Ophthalmol 2008, 86:927-928.

30. Kim KS, Chang HR, Song S: Ischaemic change after intravitreal bevacizumab (Avastin) injection for macular oedema secondary to non-ischaemic central retinal vein occlusion. Acta Ophthalmol 2008, 86:925-927.

31. Lee $\mathrm{CS}, \mathrm{Koh} \mathrm{HJ}$ : Multiple retinal haemorrhages in diabetic retinopathy after adjunctive intravitreal bevacizumab (Avastin) with pars plana vitrectomy. Acta Ophthalmol 2008, 86:812-813.

32. Brownbill P, McKeeman GC, Brockelsby JC, Crocker IP, Sibley CP: Vasoactive and permeability effects of vascular endothelial growth factor-165 in the term in vitro dually perfused human placental lobule. Endocrinology 2007 , 148:4734-4744.

33. Ehinger B: Adrenergic nerves to the eye and its adnexia in rabbit and guinea-pig. Acta Univ Lundensis 1964, 2:5-23. 
34. Hoste AM, Boels PJ, Andries LJ, Brutsaert DL, de Laey JJ: Effects of betaantagonists on contraction of bovine retinal microarteries in vitro. Invest Ophthalmol Vis Sci 1990, 31:1231-1237.

35. Laties AM: Central retinal artery innervation. Arch Ophthalmol 1967, 77:405-409.

36. Ye X, Laties AM, Stone RA: Peptidergic innervation of the retinal vasculature and optic nerve head. Invest Ophthalmol Vis Sci 1990, 31:1731-1737.

37. Ferrari-Dileo G, Davis EB, Anderson DR: Biochemical evidence for cholinergic activity in retinal blood vessels. Invest Ophthalmol Vis Sci 1989, 30:473-477.

38. Delaey C, van de Voorde J: Retinal arterial tone is controlled by a retinalderived relaxing factor. Circ Res 1998, 83:714-720.

39. Delaey $C$, Van D: V: Regulatory mechanisms in the retinal and choroidal circulation. Ophthalmic Res 2000, 32:249-256.

40. Ames A, Li YY: Energy requirements of glutamatergic pathways in rabbit retina. J Neurosci 1992, 12:4234-4242.

41. Ames A, Li YY, Heher EC, Kimble CR: Energy metabolism of rabbit retina as related to function: High cost of $\mathrm{Na}^{+}$transport. J Neurosci 1992, 12:840-853.

42. Yu D-Y, Cringle SJ: Oxygen distribution and consumption within the retina in vascularised and avascular retinas and in animal models of retinal disease. Prog Retina Eye Res 2001, 20:175-208.

43. Yu D-Y, Cringle SJ, Su E-N: Intraretinal oxygen distrubution in the monkey retina and the response to systemic hyperoxia. Invest Ophthalmol Vis Sci 2005, 46:4728-4733.

44. Yu DY, Yu PK, Balaratnasingam C, Cringle SJ, Su EN: Microscopic structure of the retina and vasculature in the human eye. In Microscopy: Science, Technology, Applications and Education. 2nd edition. Edited by Méndez-Vilas A, Díaz J. Badajoz: Formatex Research Center; 2010:867-875.

45. Sacu S, Pemp B, Weigert G, Matt G, Garhofer G, Pruente C, et al: Response of Retinal Vessels and Retrobulbar Hemodynamics to Intravitreal AntiVEGF Treatment in Eyes with Branch Retinal Vein Occlusion. Invest Ophthalmol Vis Sci 2011, 52:3046-3050.

46. Bates DO, Hillman NJ, Williams B, Neal CR, Pocock TM: Regulation of microvascular permeability by vascular endothelial growth factors. $J$ Anat 2002, 200:581-597.

doi:10.1186/1471-2415-12-10

Cite this article as: Su et al: An experimental study of VEGF induced changes in vasoactivity in pig retinal arterioles and the influence of an anti-VEGF agent. BMC Ophthalmology 2012 12:10.

\section{Submit your next manuscript to BioMed Central and take full advantage of:}

- Convenient online submission

- Thorough peer review

- No space constraints or color figure charges

- Immediate publication on acceptance

- Inclusion in PubMed, CAS, Scopus and Google Scholar

- Research which is freely available for redistribution 